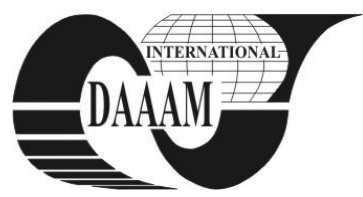

\title{
THE PRELOADING EFFECTS ON FATIGUE STRENGTH AND FATIGUE LIFE
}

\section{JINESCU, V[aleriu]; SIMA, T[eodor]; CHELU, A[ngela] \& JINESCU, C[osmin]}

\begin{abstract}
On the basis of principle of critical energy, one establishes a general relation for the correlation of the mechanical properties with the deterioration due to preloading. The effect of preloading and its sign on the fatigue strength and fatigue life is evaluated. The influence of thermal fatigue preloading on high temperature mechanical characteristics of a Cr-Mo steel quasi-static loaded was investigated.

Key words: preloading, fatigue life, thermal fatigue preloading, fatigue strength
\end{abstract}

\section{INTRODUCTION}

Previous fatigue loading induced damage to the material (Sanchez - Santana et al., 2009). A fatigue deteriorated sample, generally, behaves different from a fatigue free sample (Whittaker \& Evans, 2009).

The goal and the news of this paper is to establish general relations for the fatigue strength and fatigue life of mechanical structures, taking into consideration the deteriorations produced by preloading, as well as fatigue preloading effect on the quasistatic mechanical characteristics. In the future the influence of creep preloading and fatigue life will be analised.

\section{THE PRINCIPLE OF CRITICAL ENERGY}

One uses the principle of critical energy (Jinescu, 1984):

"The critical state in a process or phenomenon is reached when the sum of the specific energy amounts involved, considering the sense of their action, becomes equal to the value of the specific critical energy characterizing that particular process or phenomenon".

The mathematical expression of the principle is,

$$
\sum_{i}\left(\frac{E}{E_{c r}}\right)_{i} \cdot \delta_{i}=1
$$

where $\delta_{\mathrm{i}}=1 ; 0$ or -1 , if the action of specific energy $E_{\mathrm{i}}$ is in the sense, has no effect upon or opposes the process or phenomenon.

The left side of the relation (1) $P_{i}=\left(\frac{E}{E_{c r}}\right)_{i} \cdot \delta_{i}$ is the participation of the specific energy $E_{i}$.

The total participation of the specific energy, is the sum of the individual participations, $\mathrm{P}_{\mathrm{i}}$,

$$
P_{T}=\sum_{i} P_{i}
$$

For real materials, for deteriorated materials,

$$
P_{T}=P_{c r},
$$

where $\mathrm{P}_{c r}$ is the critical participation, a dimensionless parameter which ranges over an interval, $\mathrm{P}_{\mathrm{cr}} \in\left[\mathrm{P}_{\mathrm{cr}, \text { min }} ; \mathrm{P}_{\mathrm{cr} \text {,max }}\right]$, due to stochastic values of the matter characteristics. $P_{c r, m a x} \leq 1$ corresponds to the maximum probability of attaining the critical state, while $\mathrm{P}_{\text {cr,min }}$ corresponds to the minimum probability of attaining the critical state.

Generally, if: $\mathrm{P}_{\mathrm{T}}<\mathrm{P}_{\text {cr }}-$ subcritical state; $\mathrm{P}_{\mathrm{T}}=\mathrm{P}_{\text {cr }}-$ critical state is reached; $\mathrm{P}_{\mathrm{T}}>\mathrm{P}_{\mathrm{cr}}$ - supercritical state.

The critical participation depends on time, $t$, through the total deterioration $\mathrm{D}_{\mathrm{T}}$, as follows (Jinescu, 2008):

$$
P_{c r}=P_{c r}(0)-D_{T}
$$

where $\mathrm{P}_{c r}(0)$ is the value of $\mathrm{P}_{c r}$ corresponding to $t=0$.

One notes with $D_{T}$ the deterioration of matter as a dimensionless parameter: $\mathrm{D}_{\mathrm{T}}=0$ - for virgin, unstressed matter (at $\mathrm{t}=0$ ) and $\mathrm{D}_{\mathrm{T}}=1$ - for totally damaged matter.

The matter behavior is considered non-linear, as a powerlaw function, $\sigma=\mathrm{M}_{\sigma} \cdot \varepsilon^{\mathrm{k}}$.

Specific energy $E=\int \sigma \cdot d \sigma$, has the expression:

$$
\mathrm{E}=\frac{\sigma^{1 / \mathrm{k}+1}}{\mathrm{M}_{\sigma}^{1 / \mathrm{k}} \cdot(\mathrm{k}+1)} .
$$

When critical state is attained in relation (5) $\sigma$ is replaced by $\sigma_{\mathrm{cr}}$ thus the critical energy participation,

$$
\mathrm{P}(\sigma)=\frac{\mathrm{E}}{\mathrm{E}_{\mathrm{cr}}} \cdot \delta_{\sigma}=\left(\frac{\sigma}{\sigma_{\mathrm{cr}}}\right)^{\alpha+1} \cdot \delta_{\sigma},
$$

where $\alpha=1 / \mathrm{k}$ and $\delta_{\sigma}$ has the meaning of $\delta_{\mathrm{i}}$.

Under fatigue loading,

$$
E=E\left(\sigma_{a}\right)+E\left(\sigma_{m}\right)
$$

where $\sigma_{\mathrm{a}}=0.5\left(\sigma_{\max }-\sigma_{\min }\right)$ and $\sigma_{\mathrm{m}}=0.5\left(\sigma_{\max }+\sigma_{\min }\right)$.

From relations (6) and (7) results,

$$
\mathrm{P}_{\mathrm{T}}=\left(\frac{\sigma_{\mathrm{a}}}{\sigma_{\mathrm{a}, \mathrm{r}}}\right)^{\alpha+1}+\left(\frac{\sigma_{\mathrm{m}}}{\sigma_{\mathrm{m}, \mathrm{rr}}}\right)^{\alpha+1} \cdot \delta_{\sigma}
$$

where $\sigma_{\mathrm{a}, \mathrm{cr}}=\sigma_{-1}$, is the fatigue limit for samples loaded at $\mathrm{N} \geq \mathrm{N}_{0}$ and $\sigma_{\mathrm{a}, \mathrm{cr}}=\sigma_{-1}(\mathrm{~N})$ - the strength of the samples loaded at $\mathrm{N}<\mathrm{N}_{0}$; $\sigma_{\mathrm{m}, \mathrm{cr}}=\sigma_{\mathrm{u}}-$ ultimate stress.

$\sigma_{-1}(N)=f\left(\sigma_{-1} ; D(N)\right)$ is a function of fatigue limit $\sigma_{-1}$, and of deterioration produced by $\mathrm{N}$ fatigue loading cycles, $\mathrm{D}(\mathrm{N})$.

Deterioration makes fatigue strength decrease in time with $\Delta \sigma=\mathrm{f}_{\mathrm{s}}(\mathrm{D}(\mathrm{N}))$, such as $\sigma_{-1}(\mathrm{~N})=\sigma_{\mathrm{u}}-\Delta \sigma($ Fig. 1$)$.

Based on Basquin law (Basquin, 1910) $\sigma_{\mathrm{a}}{ }^{\mathrm{m}} \cdot \mathrm{N}=$ constant, from relation (8) results,

$$
P_{T}=\left(\frac{\sigma_{a}}{\sigma_{-1}}\right)^{\alpha+1} \cdot\left(\frac{N}{N_{0}}\right)^{\frac{\alpha+1}{m}}+\left(\frac{\sigma_{m}}{\sigma_{u}}\right)^{\alpha+1} \cdot \delta_{\sigma}
$$

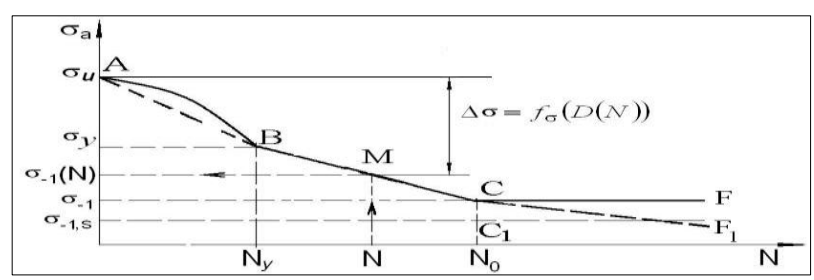

Fig. 1. Fatigue curve (Wőhler)

\section{CRITICAL PARTICIPATION}

If $\sigma_{-1}$ and $\sigma_{\mathrm{u}}$ are deterministic parameters then $\mathrm{P}_{\mathrm{cr}}(0)=1$.

The critical participation after preloading of the structure in certain conditions has the expression (4) where

$$
D_{T}=D(a)+D(-t)
$$

$\mathrm{D}(\mathrm{a})$ is the deterioration produced by crack development $a$; 
$\mathrm{D}(-\mathrm{t})=\mathrm{D}\left(-\mathrm{t} ; \sigma_{\mathrm{a}}(\mathrm{N})\right)+\mathrm{D}(-\mathrm{t} ; \sigma(\mathrm{T} ; \mathrm{t}))+\mathrm{D}\left(-\mathrm{t}_{\mathrm{cs}} ; \sigma\right) ; \quad \mathrm{D}\left(-\mathrm{t} ; \sigma_{\mathrm{a}}(\mathrm{N})\right)$ is the deterioration produced by fatigue preloading with stress amplitude $\sigma_{\mathrm{a}}$, after $\mathrm{N}$ cycles; $\mathrm{D}(-\mathrm{t} ; \sigma(\mathrm{T} ; \mathrm{t}))$ - deterioration produced by the action of stress $\sigma=$ constant, after a loading time $t$ at a temperature higher than the creep temperature;

$\mathrm{D}\left(-\mathrm{t}_{\mathrm{cs}} ; \sigma\right)$ - deterioration produced by the corrosive action of environment over the time $t_{c s}$, under stress $\sigma=$ constant.

\section{FATIGUE LIMIT, FATIGUE STRENGTH AND FATIGUE LIFE}

From relations (4) and (8) results the expression of fatigue limit of sample loaded with average stress $\sigma_{\mathrm{m}}$, having the residual stress $\sigma_{\text {res }}$ and being subject to deterioration, $D_{T}$,

$\sigma_{-1}(D)=\sigma_{-1} \cdot\left[P_{c r}(0)-\left(\frac{\sigma_{m}+\sigma_{r e s}}{\sigma_{u}}\right)^{\alpha+1} \cdot \delta_{\sigma_{m+r}}-D_{T}\right]^{\frac{1}{\alpha+1}}$

where the residual stresses have been associated to average stress, and $\delta_{\sigma_{m+r}}=1$ if $\sigma_{\mathrm{m}}+\sigma_{\text {res }}>0$ and -1 if $\sigma_{\mathrm{m}}+\sigma_{\text {res }}<0$.

$\sigma_{-1}$ and $\sigma_{-1}(\mathrm{D})$ correspond to $\mathrm{N}_{0}$ loading cycles. From relation (11) results that the fatigue limit of a sample without residual stresses $\left(\sigma_{\text {res }}=0\right)$, loaded with an average stress $\sigma_{\mathrm{m}}>0$, undergoing deterioration is lower than the fatigue limit of the virgin sample, without damage, stressed only alternant symmetrically $\left(\sigma_{\mathrm{m}}=0\right)$. The value between brackets in relation (11) depends on exponent $\alpha$ which is function of the loading rate $(0 \leq \alpha \leq 1 / \mathrm{k})$.
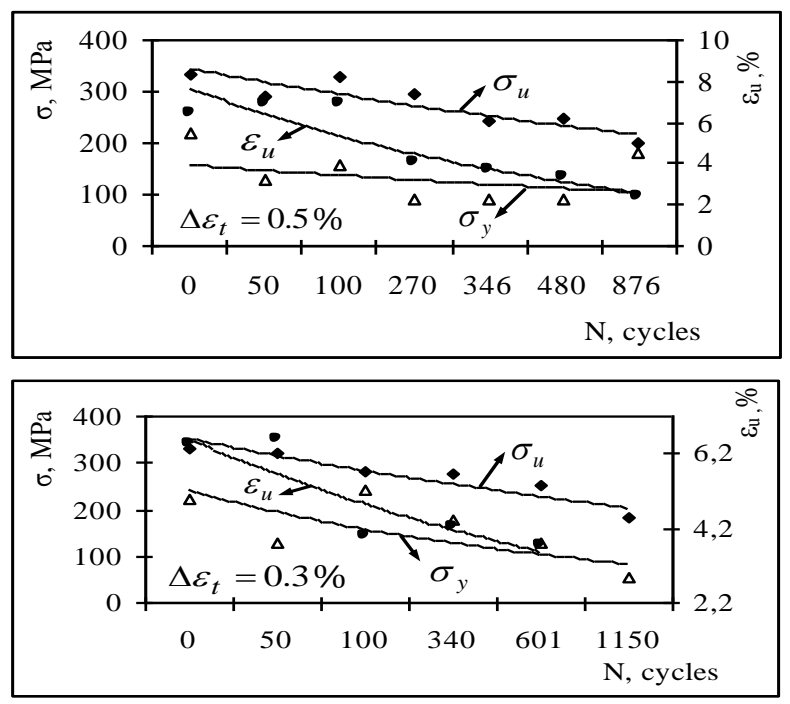

Fig. 2. Dependence of ultimate stress $(\diamond)$, yield stress $(\Delta)$ and ultimate strain (o) of a sample of steel $13 \mathrm{Cr}$ Mo 4-5 at $\mathrm{T}=530^{\circ} \mathrm{C}$, of the number of thermal fatigue preloading cycles with triangular cycle, between $60^{\circ} \mathrm{C}$ and $530^{\circ} \mathrm{C}$, for the total strain range $\Delta \varepsilon_{t}=0.5 \%$ and $0.3 \%$.

Fatigue strength of the sample with deterioration after $\mathrm{N}<\mathrm{N}_{0}$ loading cycles results from relation

$$
\sigma_{-1}(D, N)=\sigma_{-1}(D) \cdot\left(\frac{N_{0}}{N}\right)^{\frac{1}{m}}
$$

Fatigue strength of a deteriorated structure subject to $\mathrm{N}<\mathrm{N}_{0}$ loading cycles calculates with relation,

$$
\sigma_{-1, s}(D, N)=\frac{\varepsilon_{d} \cdot \gamma_{s}}{K_{\sigma}} \cdot \sigma_{-1}(D, N),
$$

where $\varepsilon_{\mathrm{d}}$ - dimensional coefficient; $\gamma_{\mathrm{s}}$ - surface quality coefficient; $K_{\sigma}$ - stress concentration factor (notch factor).

Because $\mathrm{N}<\mathrm{N}_{0}$ results $\sigma_{-1}(\mathrm{D}, \mathrm{N})<\sigma_{-1}(\mathrm{D})$. For $\mathrm{N}=\mathrm{N}_{0}$, with $\mathrm{D}_{\mathrm{T}}=0$ the relation (13) gives the fatigue limit of the structure before deterioration, $\sigma_{-1, s}=\frac{\varepsilon_{d} \cdot \gamma_{s}}{K_{\sigma}} \cdot \sigma_{-1}$.

For a virgin sample loaded with stress amplitude $\sigma_{\mathrm{a}}$ and average stress $\sigma_{\mathrm{m}}$ from relations (3), (4) and (9) results the number of loading cycles until fracture,
$N=N_{0} \cdot\left(\frac{\sigma_{-1}}{\sigma_{a}}\right)^{m} \cdot\left[P_{c r}(0)-\left(\frac{\sigma_{m}+\sigma_{r e s}}{\sigma_{u}}\right)^{\alpha+1} \cdot \delta_{\sigma_{m+r}}-D_{T}\right]^{\frac{m}{\alpha+1}}(14)$

\section{FATIGUE PRELOADING EFFECT ON THE QUASI-STATIC CHARACTERISTICS MECHANICAL}

The value of a quasi-static mechanical characteristic of a structure deteriorated through fatigue preloading can be obtained from the condition (3), where $\mathrm{P}_{\mathrm{T}} \equiv \mathrm{P}_{\sigma}$ is replaced according to relation (6). With notation $\sigma=\sigma_{\mathrm{cr}}(\mathrm{N})$ results,

$$
\sigma(N)=\sigma_{c r} \cdot\left[P_{c r}(0)-D_{T}\right]^{\frac{1}{\alpha+1}},
$$

where, in this case, $\mathrm{D}_{\mathrm{T}}=\mathrm{D}\left(-\mathrm{t} ; \sigma_{\mathrm{a}}(\mathrm{N})\right)$, and $\sigma_{\mathrm{cr}}$ value of the mechanical characteristic of the undamaged sample; $\sigma_{\mathrm{cr}}(\mathrm{N})$ is the value of the mechanical characteristic of the deteriorated structure after $\mathrm{N}$ loading cycles.

If the real value of the yield stress is calculated one replaces $\sigma_{\mathrm{cr}}=\sigma_{\mathrm{y}}$ and $\sigma_{\mathrm{cr}}(\mathrm{N})=\sigma_{\mathrm{y}}(\mathrm{N})$, and if ultimate stress is calculated, one replaces $\sigma_{\mathrm{cr}}=\sigma_{\mathrm{u}}$ and $\sigma_{\mathrm{cr}}(\mathrm{N})=\sigma_{\mathrm{u}}(\mathrm{N})$. It is obvious that $\sigma_{\mathrm{y}}(\mathrm{N})<\sigma_{\mathrm{y}}$ and $\sigma_{\mathrm{u}}(\mathrm{N})<\sigma_{\mathrm{u}}$, which have been noticed also experimentally.

In experiments performed with cylindrical tubular samples of steel $13 \mathrm{Cr}$ Mo 4-5 having the external diameter of $13 \mathrm{~mm}$ and the internal diameter of $12 \mathrm{~mm}$, these have been subjected to thermal fatigue loading through triangular cycles between $60^{\circ}$ and $530^{\circ}$. The tests have been performed with the total strain range $\Delta \varepsilon_{\mathrm{t}}=$ constant thus $\Delta \varepsilon_{\mathrm{t}}=0.3$ and $0.5 \%$, respectively.

Fatigue preloading had the effect the decrease of ultimate stress, yield stress and ultimate strain, with the increase of loading cycles number as results from figure 2 and relation (15).

\section{CONCLUSIONS}

Preloading dependent on time (fatigue, creep, corrosion, a.s.o.) determine the decrease of values of quasi-static mechanic and dynamic characteristics of many materials. In this paper have been established relations for the calculus of fatigue limit (11), fatigue strength (12) and (13) and fatigue life (14) taking into account the influence of preloading deterioration and of characteristic parameters, i.e. average stress and residual stresses. A relation (15) has been established for the calculus of ultimate stress and yield stress, considering prior deteriorations.

Experimental tests (Fig. 2) evidenced the decrease of the mechanical characteristics values following deteriorations produced by preloading, which agree to the theoretical relations established.

\section{ACKNOWLEDGEMENTS}

The author wishes to acknowledge the CNCSIS (National Council of Scientific Research in Higher Education) in Romania for their financial support for this work.

\section{REFERENCES}

Basquin, O.H. (1910). The experimental law of endurance tests, Proc. ASTM, ASTEA, pp. 625-630

Jinescu, V.V. (1984). Principiul energiei critice, Revista de Chimie, Vol. 35, No. 9, pp. 858-861, ISSN $0034-7752$

Jinescu, V.V.(2008). Calculus of the materials and process equipments deterioration, II, Revista de Chimie, Vol. 59, No. 7, pp. 785-795, ISSN $0034-7752$

Sanchez-Santana, U. et. al., (2009). Effect of fatigue damage on the dynamic tensile behavior of 6061-T6 aluminium alloy and AISI 4141T steel. Int. J. Fatigue, 31, pp. 1928-1937, ISSN 0142-1123

Whittaker, M.T. \& Evans, W.J. (2009). Effect of prestrain on the fatigue properties of Ti 834. Int. J. Fatigue, 31, pp. 1751-1757, ISSN 0142-1123 